\title{
O DISCURSO DOS FRAGMENTOS: SÓCIO-COSMOLOGIA E ALTERIDADE NA CERÂMICA GUARANI PRÉ-COLONIAL
}

\author{
ADRIANA SCHMIDT DIAS ${ }^{1}$ \\ UFRGS \\ MARIANA ARAÚJO NEUMANN ${ }^{2}$ \\ UFRGS \\ RODRIGO MONTERO ${ }^{3}$ \\ UFRGS \\ MARILISE MOSCARDINI DOS PASSOS ${ }^{4}$ \\ UFRGS \\ PEDRO VON MENGDEN MEIRELLES ${ }^{5}$ \\ UFRGS \\ ROBERTA PÔRTO MARQUES ${ }^{6}$ \\ UFRGS
}

RESUMO: De acordo com as fontes etnohistóricas do século XVII, a decoração e a variabilidade formal da cerâmica Guarani estavam relacionadas aos diferentes tipos de uso dos vasilhames, sendo a cerâmica pintada usada principalmente em situações rituais. Com o objetivo de explorar a relação entre os grafismos e as categorias funcionais de vasilhas, bem como as variações estilísticas regionais elou cronológicas apresentadas pelas amostras, analisamos coleções de cerâmicas arqueológicas do litoral norte e da região noroeste do Rio Grande do Sul. No estudo de caso aqui apresentado, sugerimos que a cerâmica pintada apresenta alto potencial para análise de problemáticas relativas à alteridade e ao universo sócio-cosmológico Guarani pré-colonial.

PALAVRAS CHAVE: Cultura material; arqueologia Guarani; arqueologia sul brasileira; análise cerâmica; cerâmica Guarani pintada.

ABSTRACT: According to the 16th century ethno historical documents, Guarani pottery decoration and formal variability were related to distinct kinds of vessel's use and painted pottery was used mainly in ritual situations. We analyze archaeological pottery collections from

\footnotetext{
${ }^{1}$ Professora Adjunta do Departamento de História e do Programa de Pós-graduação em História da UFRGS. Bolsista Produtividade em Pesquisa CNPq. E-mail: dias.a@uol.com.br .

${ }^{2}$ Mestre pelo Programa de Pós-graduação em História da UFGRS. E-mail: marinene@yahoo.com .

${ }^{3}$ Acadêmico do curso de Artes Visuais da UFRGS. E-mail: rodrimontero@gmail.com .

${ }^{4}$ Acadêmica do curso de História da UFRGS. E-mail: marimpassos@yahoo.com.br .

${ }^{5}$ Acadêmico do curso de História da UFRGS. E-mail: pmeirelles@gmail.com .

${ }^{6}$ Acadêmica do curso de História da UFRGS. E-mail: rob.marq@yahoo.com.br .
}

Espaço Ameríndio, Porto Alegre, v. 2, n. 2, p. 5-34, jul./dez. 2008. 
ADRIANA SCHMIDT DIAS et al - O discurso dos fragmentos ...

Rio Grande do Sul North shore and Norwest region, seeking to explore the relationship between graphic patterns and distinct functional types of vessels, as well the regional and/or chronological stylistic variation of the sample. In the case study here presented, we suggest that painted pottery has high potential for the analysis of issues related to pre-colonial Guarani alterity and their social cosmological universe.

KEYWORDS: Material Culture; Guarani archaeology; South Brazilian archaeology; pottery analyses; Guarani painted pottery.

\section{Introdução}

Nossa proposta no presente trabalho é discutir o potencial da cultura material Guarani pré-colonial para os estudos de arte indígena, enfatizando os grafismos associados à cerâmica arqueológica. As datações mais antigas para registros arqueológicos Guarani no sul do Brasil remontam a 2.000 anos, estando a cultura material estilisticamente relacionada aos contextos amazônicos, destacando-se nesta associação a cerâmica policrômica. A cerâmica arqueológica Guarani apresenta alta variabilidade formal, relacionada às distintas categorias funcionais de vasilhames, o que influencia o tipo de tratamento de superfície. De acordo com as fontes etnohistóricas do século XVII, a cerâmica pintada estava predominantemente relacionada à preparação e consumo de bebidas fermentadas (cauim), principalmente em situações rituais. No registro arqueológico estas vasilhas se encontram associadas também a contextos funerários.

Partindo do princípio de que os grafismos presentes na cerâmica podem nos remeter ao universo sócio-cosmológico dos grupos que a produziram, sugerimos que estas categorias artefatuais e seus grafismos apresentam alto potencial para o estudo dos modos de ser e, em última instância, das alteridades preservadas no contexto arqueológico. Embora o estudo da cerâmica Guarani tenha avançado muito no tocante à relação entre forma e função das vasilhas, raros são os trabalhos que analisaram especificamente os grafismos quanto às suas características, variabilidade e conexões com conteúdos de natureza simbólica. Buscando preencher esta lacuna, desenvolvemos um estudo comparativo de coleções de cerâmicas arqueológicas Guarani 
ADRIANA SCHMIDT DIAS et al - O discurso dos fragmentos ...

com o objetivo de analisar a relação entre os grafismos e as categorias funcionais de vasilhas, bem como as variações estilísticas regionais e/ou cronológicas apresentadas pelas amostras. Para tanto, foram analisadas coleções de duas distintas áreas do Rio Grande do Sul, associadas ao Litoral Norte e à região noroeste do Estado, com datações que variam entre 1000 e 200 anos antes do presente.

\section{Arqueologia Guarani no Sul do Brasil: elementos para uma História de longa duração}

A arqueologia Guarani desenvolvida no sul do Brasil nas últimas quatro décadas pode ser dividida em duas tradições de pesquisa. A primeira está relacionada ao enfoque histórico-cultural associado à atuação do Programa Nacional de Pesquisas Arqueológicas (PRONAPA). Esta enquadrou os contextos arqueológicos Guarani na Sub-tradição Corrugada que caracterizaria os sítios meridionais da Tradição Cerâmica Tupiguarani, estendendo-se ao longo da costa Atlântica até o nordeste do país ${ }^{7}$. Uma segunda vertente da arqueologia Guarani deriva da revisão destas propostas, iniciada a partir da década de 1980, por José Justiniano Proenza Brochado. Participante do PRONAPA em sua fase de implantação, Brochado foi um dos primeiros a questionar os resultados do Programa referentes à interpretação dos contextos arqueológicos Guarani. Embora em termos teóricos suas propostas bebam das mesmas fontes do PRONAPA, a influência de Donald Lathrap em seu trabalho trouxe novas luzes para a elaboração de um modelo ecológico sob a dinâmica populacional Guarani, a partir de sua origem Amazônica (BROCHADO, 1984).

Baseado na relação entre estudos lingüísticos e arqueológicos, o autor propõe que a origem das proto-línguas da família Tupi-guarani teria se dado há aproximadamente 5.000 anos atrás na Amazônia Central. Por sua vez, esta diferenciação lingüística apresentaria correlação na cultura material, representada pelo surgimento de

\footnotetext{
${ }^{7}$ Críticas ao modelo proposto pelo PRONAPA referente à arqueologia Guarani podem ser encontradas em Noelli (1993 e 1999/2000) e Soares (1997).
} 
ADRIANA SCHMIDT DIAS et al - O discurso dos fragmentos ...

diversas tradições cerâmicas a partir da Tradição Policrômica Amazônica ${ }^{8}$, sendo o processo de expansão destas tradições resultante de migrações associadas à pressão demográfica. O modelo de dispersão populacional de Brochado segue uma lógica de colonização dos principais cursos fluviais, sempre motivada por causas demográficas e centrada em ambientes florestais relacionados à concepção de sistema de assentamento amazônico original. No início da era Cristã, estas migrações teriam resultado em dois grandes blocos culturais, de origem comum, mas com características materiais distintas. A sub-tradição Guarani $^{9}$ teria se expandido desde a Amazônia até a foz do Rio da Prata, seguindo os cursos dos rios Paraguai, Paraná e Uruguai, circundando o planalto central brasileiro, em sua porção oeste e sul. A dispersão proto-Guarani em direção ao sul, possivelmente, deu-se através dos rios Madeira e Guaporé, com perdas das formas originais dos vasilhames e técnicas decorativas, relacionadas à sub-tradição Guarita, e aquisição de novas formas e tratamentos de superfície, como o corrugado, através de contato com as populações do leste boliviano e peruano. Uma segunda leva migratória, por sua vez, estendeu-se da Amazônia Central em direção à foz do Amazonas, onde em contato com as populações do baixo Amazonas a cerâmica adquiriu as características da sub-tradição Tupinambá que ocupou a costa Atlântica, do nordeste ao litoral paulista.

Partindo das fontes históricas do século XVII, Noelli (1993) e Soares (1997) sugerem que os domínios territoriais dos Guarani précoloniais refletiam os laços de parentesco e reciprocidade em três níveis espaciais inclusivos: Guará, tekohá e teii. O Guará é um conceito sóciopolítico que diz respeito a uma região definida, cuja manutenção é garantida por alianças entre várias aldeias, estando sob a liderança de uma pessoa de grande prestígio político e espiritual que dominava extensos trechos das bacias hidrográficas. As fontes históricas jesuíticas apontam para a existência no Rio Grande do Sul de pelo menos cinco destas parcialidades (Guarâ): os Guarani, os Tape, os Caágua, os Carijó

\footnotetext{
${ }^{8}$ Para um aprofundamento nas discussões lingüísticas e arqueológicas sobre o centro de origem dos Tupi ver Noelli (1993, 1996a, 1996b, 1998), Urban (1996) e Viveiros de Castro (1996).

${ }^{9}$ A influência do modelo proposto por Brochado na arqueologia do sul do Brasil, fez com que nas duas últimas décadas, se tornasse de uso comum entre as novas gerações de pesquisadores referir-se a esta cerâmica como pertencente à Tradição Guarani, termo que incorporamos neste trabalho, embora não haja uma definição formal neste sentido em nenhuma publicação do autor.
}

Espaço Ameríndio, Porto Alegre, v. 2, n. 2, p. 5-34, jul./dez. 2008. 
ADRIANA SCHMIDT DIAS et al - O discurso dos fragmentos ...

e os Arachane. Os Guarani ocupariam a região das Missões, nas bacias dos rios ljuí, Piratini e I-Camaquã, a noroeste do Estado, tendo sua área por limite sul o vale do rio Ibicuí. A região habitada pelos Tape teria como limites naturais, a oeste, o alto rio Ibicuí; ao norte, a Serra Geral; a leste, o vale do rio Caí e ao sul, a Serra dos Tapes. O território dos Tape corresponderia à parte leste da Depressão Central Gaúcha e às regiões mais altas do planalto, a oeste do alto rio Taquari. Os territórios dos Guarani e Tape seriam os com maior densidade demográfica quando do contato com os jesuítas. Os Caágua teriam sofrido mais intensamente a ação das bandeiras paulistas, com intensos deslocamentos populacionais, sendo possivelmente seu território original delimitado pela bacia do rio Jacuí ao sul, pelo rio Taquari, a oeste, e pela Serra do Mar, a leste. Por fim, a planície costeira abrigaria outras duas parcialidades, estando os Carijó na porção norte do litoral atlântico e os Arachane nas margens da Lagoa dos Patos, ao sul, sendo os primeiros também fortemente afetados pela ação das bandeiras (SOARES, 1997).

Os Guará são compostos por unidades sócio-econômicas aliadas, denominadas tekohá, que possuem uma área definida, delimitada por arroios ou rios e utilizada de forma comunal e exclusiva pelo grupo local. O tekohá corresponde ao espaço no qual se reproduziam as relações econômicas, sociais e político-religiosas essenciais à vida Guarani, sendo formados por teii isolados ou agrupados, em função das condições locais e políticas. O teii representa a parcialidade ou família extensa, sendo designada de teii oga a casa onde vivia a linhagem e de amundá o local da aldeia ou sede do tekohá. Uma teii oga poderia abrigar até 60 famílias nucleares, podendo as aldeias de grande porte ser habitadas por, aproximadamente, 2000 pessoas. Em função de sistemas de alianças políticas, estima-se que um grande Guará poderia conjugar em torno de 40 tekohá, sendo sua população total superior a 80.000 habitantes (NOELLI, 1993; SOARES, 1997).

As formas bélicas de conquista e manutenção dos territórios de domínio desenvolvidas pelos Guarani sugerem que conflitos e disputas bélicas marcaram o tipo de relação com outras populações précoloniais. Desta forma, a colonização da região sul pelos Guarani, determinou o extermínio e/ou absorção cultural dos caçadores coletores do interior e do litoral, bem como restringiu as áreas de domínio dos 
ADRIANA SCHMIDT DIAS et al - O discurso dos fragmentos ...

Kaingang e Xokleng às Terras Altas do planalto sul brasileiro. A prática da guerra Guarani, associada à captura de prisioneiros para o ritual antropofágico, estaria relacionada à necessidade de expansão das fronteiras territoriais e de manutenção das áreas já ocupadas. A guerra de expansão de fronteiras seria a primeira etapa da conquista territorial, com a desagregação política dos habitantes originais e instalação das primeiras áreas de manejo. O contínuo processo de expansão de fronteiras deixaria para trás os territórios colonizados por uma população estável com condições de manter e manejar as terras conquistadas. Se no momento de expansão de fronteiras era desenvolvida a guerra contra grupos não-Guarani, posteriormente, a manutenção dos espaços já conquistados desencadeava entre os Guarani, disputas pela instalação e manutenção das melhores áreas. A guerra seria também um veículo de promoção na hierarquia social Guarani, pois é nela que a liderança temporária das chefias locais (tuvichâ) se faria sentir. O aumento do prestígio das lideranças no teii se daria através da possibilidade de manifestar valentia e capacidade de reunir pessoas pelos convites intercomunitários para formação das alianças de guerra ou ampliar a família extensa, seja pelas alianças de casamento, seja pelo rapto das mulheres dos inimigos. O aumento demográfico contribui neste processo, levando a instalação gradativa de aldeias em locais cada vez menos propícios. No caso do Rio Grande do Sul, este ritmo de expansão paulatinamente se dirigiria para os rios que tem suas nascentes no planalto, enquanto o ângulo de inclinação do solo mantém-se favorável à agricultura, obedecendo a um limite de 400 metros de altitude (NOELLI, 1993; SOARES, 1997).

As pesquisas arqueológicas indicam a presença Guarani nas bacias hidrográficas dos rios Paranapanema, Uruguai e Jacuí entre 2000 e 1500 anos AP. Para o Estado do Rio Grande do Sul os sítios Guarani encontram-se datados a partir de 1800 anos AP para o vale médio do rio Jacuí, 1070 anos AP para o litoral norte, 890 anos AP para o litoral sul, 800 anos AP para o vale do rio Santa Maria, 745 anos AP para o vale do rio Caí, 610 anos AP para a Bacia do Lago Guaíba e 225 anos AP para o vale do rio da Várzea. Apresentando uma dispersão que atinge todo o território gaúcho, estima-se que no século XVI a população Guarani do Estado abrangesse mais de 200.000 indivíduos. Os sítios arqueológicos 
ADRIANA SCHMIDT DIAS et al - O discurso dos fragmentos ...

que caracterizam as antigas aldeias podem apresentar manchas escuras de solo orgânico demarcando os pisos das casas, associadas a concentrações de artefatos cerâmicos e líticos. Estas manchas de terra preta possuem formato elíptico ou circular e podem atingir até 30 metros de comprimento, ocorrendo de forma isolada ou formando conjuntos de até seis casas por aldeia (NOELLI, 1993 e 1999/2000; SCHMITZ, 1991).

Quanto ao estudo das cerâmicas arqueológicas Guarani, os trabalhos desenvolvidos por Brochado e colaboradores, entre as décadas de 1970 e 1990, incorporaram à análise referenciais etnoarqueológicos, baseados em fontes etno-históricas ${ }^{10}$ do período do contato, permitindo a interpretação funcional da variabilidade formal e decorativa dos vasilhames (BROCHADO, 1977; BROCHADO, MONTICELLI e NEUMANN, 1990; BROCHADO \& MONTICELLI, 1994; LA SALVIA e BROCHADO, 1989; NOELLI e BROCHADO, 1998). Os resultados destas pesquisas indicam que a cerâmica Guarani apresenta uma grande variabilidade de formas e padrões decorativos associados a distintas categorias funcionais de vasilhames. As panelas (yapepó), apresentam tratamento de superfície, em geral corrugado, podendo também se apresentar alisado, ungulado ou escovado. Suas dimensões podem atingir até $90 \mathrm{~cm}$ de altura e 100 $\mathrm{cm}$ de diâmetro de boca, com capacidade máxima de até 120 litros. Outras categorias de vasilhas cerâmicas voltadas à preparação de alimentos são as caçarolas (ñaetâ) e os tostadores de farinha de mandioca (ñamopyu). As vasilhas para conter líquidos (cambuchi) e produzir bebida fermentada (cauim), apresentam pintura externa, com padrões geométricos vermelho e, mais raramente, preto, elaborados sobre um fundo branco. Suas dimensões variam entre 10 e $100 \mathrm{~cm}$ de altura e 18 a $70 \mathrm{~cm}$ de diâmetros de boca, podendo apresentar volume de até 150 litros. Também apresentam pintura externa os cântaros para beber cauim (cambuchi caguabâ) e os pratos (ñambé ou tembiru) (LA SALVIA e BROCHADO, 1989). As grandes dimensões das vasilhas para cozinhar (yapepó) e preparar bebidas fermentadas (cambuchi) indicam práticas de preparação e consumo coletivo de alimento e bebida nas festas e rituais, apresentando também uma função secundária,

\footnotetext{
${ }^{10}$ Com ênfase para o Tesoro de la Lengua Guarani, escrito por Montoya entre 1612 e 1617.
} 
ADRIANA SCHMIDT DIAS et al - O discurso dos fragmentos ...

associada às práticas funerária (LA SALVIA e BROCHADO, 1989; NOELLI, 1993 e 1999/2000; SCHMITZ, 1991).

Até o presente, raros estudos contemplaram a análise dos padrões gráficos representados na cerâmica Guarani. Um primeiro esforço neste sentido foi realizado na década de 1950 por Pedro Ignácio Schmitz. Sob a influência teórica do histórico-culturalismo, para o autor a variação dos padrões gráficos observados nas coleções arqueológicas representaria elementos decorativos, destituídos de significado simbólico $^{11}$. Esta postura foi questionada na década de 1980 por La Salvia e Brochado que sugerem uma relação estreita entre o tratamento de superfície e aspectos morfológicos e funcionais das vasilhas Guarani (LA SALVIA e BROCHADO, 1989; BROCHADO, MONTICELLI e NEUMANN, 1990; BROCHADO e MONTICELLI, 1994). Estes autores sugerem que os motivos da pintura pertencem a uma "memória tradicional", sendo sua escolha não arbitrária, mas ligada a tradições cosmológicas. Portanto, os autores propõem a análise estrutural dos motivos, registrando as linhas e seus componentes, sua posição e espessura, sua distribuição na superfície, bem como a cor e natureza das tintas. Seriam estes aspectos que poderiam determinar elementos cronológicos, espaciais e sociais relacionados ao grafismo cerâmico. Contudo os autores advertem que a interpretação dos motivos seria limitada, pois nos relatos de cronistas dos séculos XVI e XVII, não há registro de seu significado tradicional (LA SALVIA e BROCHADO, 1989, p. 106-107). Procurando aprofundar estas reflexões, na década de 1990 Fernanda Tocchetto (1996) propõe uma tentativa de interpretação do conteúdo gráfico da cerâmica Guarani através da articulação entre arqueologia e etnologia. Buscando apoio nos trabalhos de Nimuendaju e Cadogan, a autora procurou nos relatos mitológicos dos Guarani de São Paulo e do Paraguai unidades que pudessem explicar o modelo formal dos grafismos. Destaca-se o relato referente aos mitos de criação do mundo, nos quais a descrição da cruz que representaria a "escora da terra" é associada pela autora a um grafismo recorrente na cerâmica Guarani, em especial nos cambuchi.

\footnotetext{
11 "De um modo geral podemos afirmar que, tanto as formas, quanto os motivos ornamentais que apresentamos são simples e, ao menos em parte, artísticos, de uma arte singela, como era próprio de um povo sem grande cultura e sem moradia sólidas" (SCHMITZ, 1959, p. 274). Mais tarde o autor, reafirma sua postura: "Especialmente a pintura dava um aspecto agradável ao vasilhame e mostrava que o grupo tinha vencido a mera subsistência e investia algum tempo em arte" (SCHMITZ, 1991, p. 307).
} 
ADRIANA SCHMIDT DIAS et al - O discurso dos fragmentos ...

Outro elemento presente na cerâmica, o motivo de losango, foi relacionado pela autora à representação da serpente, elemento presente em relatos de criação coletados por Cadongan ${ }^{12}$ (TOCCHETTO, 1996). Esta abordagem encontrou eco recentemente, nos estudos de André Prous (2007) que propõe uma leitura dos grafismos das cerâmicas arqueológicas Tupinambá relacionadas ao ritual antropofágico, associando determinados padrões geométricos a representações de partes do corpo humano, como o crânio, os intestinos e o cérebro.

Nossa proposta, mais que oferecer uma identificação do significado dos motivos aplicados na pintura de diferentes vasilhas, visa agregar uma perspectiva contextual ao estudo dos grafismos Guarani, considerando a morfologia, a estrutura e as regras de composição dos padrões. Partimos do princípio de que estes elementos, empiricamente observáveis nas peças, permitem levantar hipóteses sobre o papel que a pintura de certas vasilhas poderia desempenhar num contexto sóciopolítico complexo como o acima discutido. Estudos recentes sobre as artes gráficas entre grupos indígenas ameríndios (GALLOIS, 1992; MULLER, 1992; VAN VELTHEM, 1998; VIDAL e MULLER, 1987) demonstram a importância que a pintura dos corpos e dos artefatos possui na produção e comunicação de uma identidade social própria, determinando os limites entre diferentes esferas de exterioridade - seja um exterior cosmológico (natureza e sobrenatureza em oposição à humanidade), seja um exterior sociológico (diferentes grupos indígenas com os quais se divide ou disputa um território). Neste sentido, sugerimos que o estudo dos grafismos da cerâmica Guarani pré-colonial pode nos apontar semelhanças e diferenças na forma de sua utilização e revelar contextos de produção de identidades Guarani, associadas às diferentes parcialidades que ocuparam as regiões em análise, o litoral norte e o noroeste do Estado.

\section{O discurso dos fragmentos em contexto: aportes para o estudo dos grafismos das cerâmicas arqueológicas Guarani}

\footnotetext{
${ }^{12}$ André Prous (2007) coloca em dúvida a interpretação apresentada por Tocchetto, questionando se a relação entre os grafismos e os mitos de criação na cerâmica Guarani não teria sido influenciada pelos jesuítas.
} 
Embora o estudo da cerâmica Guarani tenha avançado muito no tocante à relação entre forma e função das vasilhas, sendo esta a ênfase da maioria dos trabalhos publicados atualmente, os raros estudos que analisaram especificamente os grafismos pouco exploraram suas características contextuais. Buscando preencher esta lacuna, desenvolvemos um estudo comparativo de coleções de cerâmicas arqueológicas Guarani com o objetivo de analisar a relação entre os grafismos e as categorias funcionais de vasilhas, enfatizando aspectos de sua variabilidade interna e suas variações estilísticas em termos regionais e/ou cronológicos. Destacamos que esta é uma proposta exploratória que busca avaliar em que medida o estudo dos grafismos presentes na cerâmica Guarani pré-colonial podem nos remeter ao universo sócio-cosmológico dos grupos que a produziram, abrindo novas vias de acesso a compreensão dos modos de ser e das alteridades materializadas no registro arqueológico.

Para este estudo utilizamos como referência as coleções de vasilhas Guarani inteiras, depositadas junto ao Museu Arqueológico do Rio Grande do Sul (MARSUL), que estavam associadas a distintos contextos arqueológicos do litoral norte e do vale do rio da Várzea, Estado do Rio Grande do Sul, áreas pesquisadas por Eurico Miller nas décadas de 1960 e 1970. A partir de uma triagem inicial, direcionada pelo grau de preservação e integridade dos padrões gráficos, foram selecionadas sete vasilhas pintadas inteiras de diferentes categorias funcionais, associadas a quatro distintos sítios arqueológicos, sendo estas dois cambuchi (sítios RS-LN-47 e RS-VZ-41), dois cambuchi caguabá (sítios RS-LN-47 e RS-VZ-41) e três tembiru (sítios RS-LN-35 e RS-VZ-3). Para complementação da análise de variabilidade dos padrões gráficos foi também analisada a coleção de fragmentos pintados do sítio RS-LN-35, totalizando 21 peças. O registro dos grafismos foi feito a partir de três técnicas conjugadas: fotografias com máquina fotográfica digital com definição de 7.1 mega pixels, decalques e reconstrução de formas funcionais para a coleção de fragmentos do sítio RS-LN-35, baseado na metodologia proposta por Brochado (BROCHADO, MONTICELLI e NEUMANN, 1990; BROCHADO e MONTICELLI, 1994).

A metodologia empregada para coleta dos dados variou de acordo com as características do tipo de suporte. Para os fragmentos, foram 
realizados decalques com películas plásticas que posteriormente foram scanedos e digitalizados no programa corel draw. Para as peças inteiras foi realizado o decalque sobre vários recortes de plástico transparente, devidamente numerados. Uma vez decalcada completamente, foram tiradas fotografias digitais da peça com os decalques, permitindo o registro dos grafismos na sua disposição original. Para seguir uma ordem padrão de fotografias, considerou-se o número de tombo inscrita no interior de cada peça como referencia (registrado com a letra $\mathrm{T}$, seguida de um numero de catálogo institucional), da qual uma linha imaginaria segue dividindo em duas partes a vasilha. Uma outra linha imaginaria dividia a peça no sentido transversal à primeira. Este sistema de notação permitiu estabelecer quatro pontos fixos para cada vasilha e assim determinar quatro vistas padrão para cada peça (Figura 1).

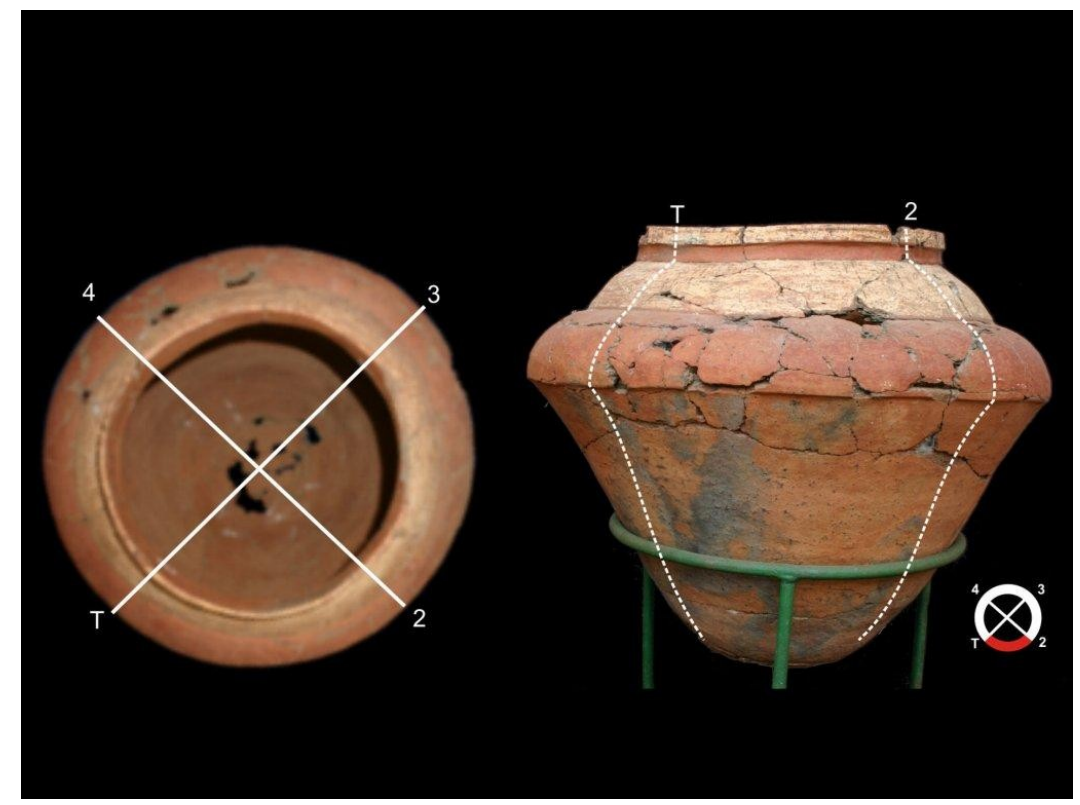

Figura 1 - Representação gráfica do método de registro utilizado

No caso dos cambuchi caguaba a visibilidade clara dos grafismos permitiu que a representação gráfica fosse realizada diretamente a partir das fotografias digitais, seguindo a notação acima especificada, sem a necessidade de utilizar os decalques plásticos. Neste caso, as características das peças permitiram uma segunda representação gráfica que permite a compreensão global do grafismo: uma reprodução plana e continua do mesmo. Para isto foram realizadas aproximadamente 20 
ADRIANA SCHMIDT DIAS et al - O discurso dos fragmentos ...

fotografias em seqüência de toda a circunferência da peça e posteriormente, recortaram-se os segmentos centrais de cada fotografia, sendo estes remontados seguindo sua ordem que resultou em uma vista em panorama da peça. A partir desta base de dados foi realizado o decalque do grafismo digitalizado em programa gráfico (corel draw). Decidiu-se por este sistema para minimizar as deformações decorrentes da própria representação em duas dimensões, de um desenho realizado sobre um suporte tridimensional. No entanto, é importante destacar que as fotografias abrangem uma área maior a dos segmentos padrão, em função da forma irregular das peças. No caso dos cambuchi, a curvatura pronunciada das peças fez com que os grafismos localizados nos extremos laterais de cada fotografia ficassem deformados pelo efeito da perspectiva. Por tal motivo, optou-se por restringir a representação gráfica às áreas demarcadas por pontos prédeterminados (i.e, T-2; 2-3; etc).

Ao tratar dos padrões gráficos de cerâmicas arqueológicas, cabe ressaltar que o grau de integridade das informações analisadas é determinado pela natureza dos processos de formação natural e cultural que geraram o contexto arqueológico, pelos métodos de campo empregados e pelas técnicas de curadoria e condições de acondicionamento das coleções nas Instituições depositárias. No caso das coleções Guarani do sul do Brasil, os contextos arqueológicos a céu aberto que representam os locais das antigas aldeias têm sofrido intensos processos de turbação nas últimas décadas devido a ação da agricultura mecanizada e da expansão das malhas urbanas.

Igualmente, as características dos solos que compõe as matrizes sedimentares dos sítios e a ação de agentes tafonômicos variados, como a chuva, a erosão e o vento, contribuem para uma preservação diferencial dos artefatos e, em particular, das cerâmicas pintadas que sofrem processos de desgaste e decomposição de seus padrões gráficos. Igualmente, as metodologias de campo empregadas representam um papel fundamental quanto à integridade das informações apresentadas e a amplitude das interpretações decorrentes, podendo revelar conjuntos arqueológicos relacionados a áreas de atividades específicas nas antigas aldeias, cujos artefatos apresentarão características e graus de preservação variados. No caso Guarani, a 
ADRIANA SCHMIDT DIAS et al - O discurso dos fragmentos ...

maior parte das pesquisas de campo realizadas até o presente centraram-se em coletas superficiais de fragmentos cerâmicos a fim de traçar cronologias relativas dos padrões decorativos. As poucas escavações em áreas amplas realizadas ocorreram no interior das casas extensas ou na periferia destas, estando, na maior parte das vezes, a cerâmica associada a áreas de descarte das zonas domésticas (lixeiras), apresentando alto grau de fragmentação (SCHMITZ et al, 1990; ROGGE, 1996; CARLE, 2002; SOARES, 2005).

Em ambos os casos, os fatores naturais atuais e culturais pretéritos afetam a integridade de preservação das amostras de cerâmicas pintadas. A exceção a este quadro está representada pelos contextos funerários associados às vasilhas cerâmicas inteiras. Contudo, a maior parte das coleções de vasilhas inteiras atualmente depositadas em Museus e Instituições Universitárias do Estado, são decorrentes de doações derivadas de achados ocasionais por ocasião da atividade agrícola ou de pesquisas arqueológicas exploratórias realizadas nos anos 60 e 70, sendo as informações contextuais escassas. Mesmo neste último caso, as características das matrizes sedimentares agressivas, associadas aos tratamentos recebidos pelos artefatos em laboratório, relacionados à limpeza e curadoria das peças, contribuíram para gerar uma base de dados limitada quanto ao estudo de padrões gráficos das cerâmicas Guarani.

Um exemplo deste quadro está representado por um exemplar de cambuchi de grandes dimensões (número de tombo T-1187), associado ao sítio RS-LN-48: Bassani 3, situado no município de Osório. Resgatada por Miller na década de 1970 em um sítio habitação, composto sete manchas pretas representando fundos de casas, distribuídas em semi-circulo, esta vasilha que apresentava um alto grau de fratura, após limpeza e restauro, apresenta apenas alguns fragmentos cujo padrão de pintura pôde ser decalcado, impossibilitando uma análise mais aprofundada (Figura 2). 


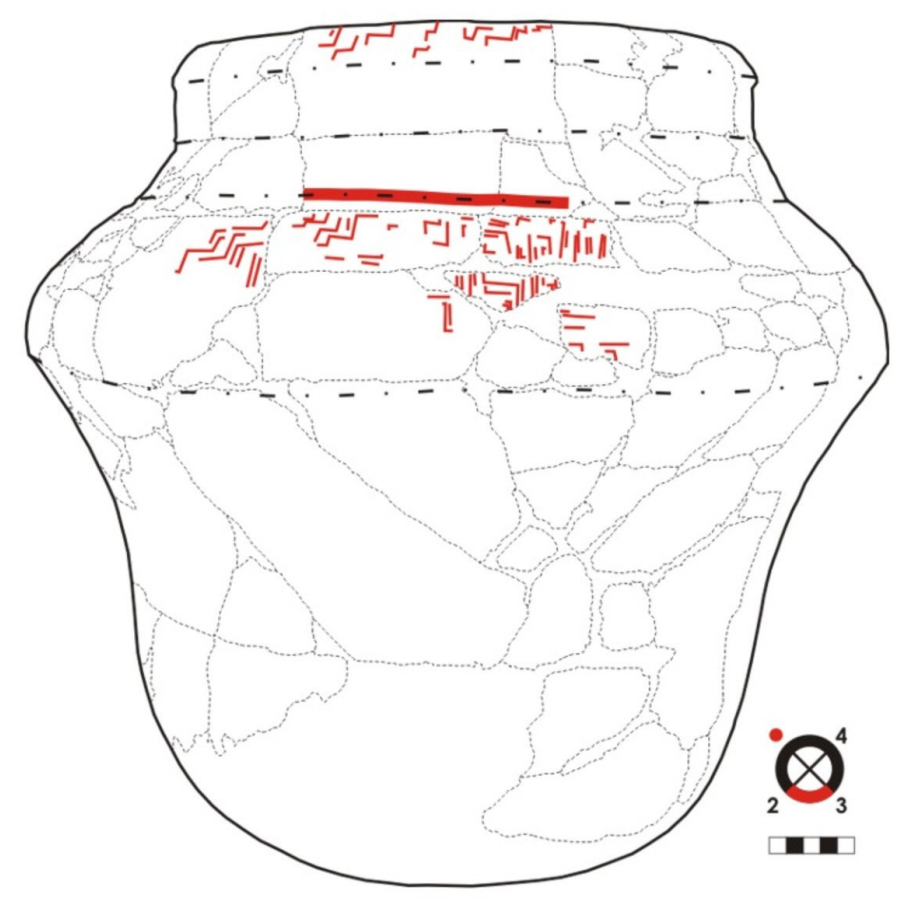

Figura 2 - Cambuchi (T 1187) - Sítio RS-LN-48: Bassani 3, Osório (RS)

Levando em consideração estes fatores, o critério fundamental que orientou nossa seleção junto ao acervo do MARSUL centrou-se nas possibilidades de análise de vasilhas que apresentassem bom estado de preservação dos padrões gráficos em associação com contextos deposicionais devidamente documentados. Em função destes critérios, selecionamos as coleções de quatro sítios arqueológicos. O primeiro diz respeito ao sítio RS-LN-47: Calipso, localizado no município de Osório, distrito de Faxinal, escavado por Eurico Miller em 1971. Formado por cinco manchas de terra preta, com disposição oval, que correspondiam aos remanescentes das casas extensas que compunham a aldeia, neste sítio foram identificados sete estruturas funerárias, sendo dois enterramentos em covas e cinco enterramentos em urnas. Dentre a coleção arqueológica associada ao sítio foram recuperadas apenas três vasilhas inteiras, das quais duas apresentam bom estado de preservação 
ADRIANA SCHMIDT DIAS et al - O discurso dos fragmentos ...

dos padrões gráficos: um cambuchi caguaba (número de tombo T-476) e um cambuchi (número de tombo T-1184).

A fim de ampliar a amostra relativa aos padrões gráficos do litoral norte do Estado, incluímos a coleção de fragmentos pintados do sítio RS-LN-35: Bassani 1, localizado no município de Capão da Canoa (coordenadas geográficas $50^{\circ} 07^{\prime} \mathrm{W}$ e $29^{\circ} 45^{\prime} \mathrm{S}$ ). Este sítio era formado por uma mancha preta com 70 metros de comprimento e 45 de largura, na qual foram realizados dois cortes estratigráficos. No primeiro (número de catálogo 648), com $2 \times 2$ metros, foram recuperadas três yapepó inteiros (números de tombo T-484, T-581 e T-582) e no segundo (número de catálogo 649), com $3 \times 3$ metros e 40 centímetros de profundidade, foram recuperadas três tembirú inteiros, dos quais selecionamos um para análise em função do grau de preservação da pintura (número de tombo T-122). Este sítio apresentou uma concentração de carvão entre 20 e 30 centímetros de profundidade que gerou duas datações radiocarbônicas de $870 \pm 100$ AP ou 1080 AD (SI 412) e 1070 1110 AP ou 880 AD (SI 413). Do conjunto total de 1192 fragmentos que compõe esta coleção, apenas 21 apresentaram padrões de pintura passíveis de análise, tendo sido possível identificar um fragmento de tembiru (presente nesta análise) e 14 bordas de cambuchi caguabá.

Buscando estabelecer um parâmetro de variação regional para esta análise selecionamos três vasilhas pintadas de outros dois contextos arqueológicos da porção oeste do Estado. O sítio RS-VZ-41: Jaboticaba 1 está localizado na margem esquerda do Rio Uruguai, município de Tenente Portela, distrito Esquina Jaboticaba (coordenadas geográficas $53^{\circ} 44^{\prime} \mathrm{W}$ e $27^{\circ} 10^{\prime} \mathrm{S}$ ), sendo composto por três manchas pretas que representam pisos de habitações e dez estruturas funerárias. O sítio possui uma datação radiocarbônica de $225 \pm 55$ AP ou 1725 AD (SI - 701), obtida a partir de uma escavação que atingiu a profundidade de $50 \mathrm{~cm}$ de onde foram recuperadas cinco vasilhas inteiras associadas a contextos funerários: dois yapepó (números de tombo T-138 e T162), um cambuchi (número de tombo T-163), um cambuchi caguaba (número de tombo T-139) e um ñaetá (número de tombo T-296). A avaliação das demais coleções de vasilhas inteiras da região do rio da Várzea indicou um baixo grau de preservação dos padrões pintados, 
ADRIANA SCHMIDT DIAS et al - O discurso dos fragmentos ...

associado à ausência de informações contextuais, sendo agregada a esta análise apenas um exemplar de tembiru associado a um poço teste de $70 \mathrm{~cm}$ de profundidade realizado no sítio RS-VZ-3: Porto Lucena (número de tombo T-659).

Apesar das distâncias geográficas e das diferenças cronológicas de 600 anos indicadas pelas datações obtidas, em ambas as regiões sob estudo os sítios caracterizaram-se pela associação de distintas categorias funcionais de vasilhas ao ritual de inumação, estando estas relacionadas à preparação de alimentos (yapepó e nãetâ), a preparação de bebidas fermentadas e acondicionamento de líquidos (cambuchi) e ao ato de servir líquidos (cambuchi caguabâ) e alimentos (tembiru). No caso do sítio RS-LN-47 a documentação de campo é a mais completa, permitindo observar dois padrões distintos de sepultamento. O primeiro caso corresponde a um cambuchi caguabá associado a um enterramento primário estendido em decúbito dorsal, depositado de forma a cobrir a face do indivíduo. Todo o restante do acompanhamento funerário está representado por fragmentos de cerâmica corrugada, associada a panelas (yapepó) concentrados nos pés e na cabeça do indivíduo. No segundo, observa-se um cambuchi que contém no seu interior um sepultamento primário fletido. O grau de alteração e fragmentação desta amostra, associada à ausência de informações quanto à escavação não permite observar a associação de outras categorias de cerâmica neste sepultamento.

Destaca-se que neste contexto ambas vasilhas pintadas, embora correspondam a duas categorias funcionais distintas, possuem o mesmo padrão de representação gráfica, distribuído de acordo com as mesmas regras de composição:

a) Os padrões geométricos vermelhos estão sobrepostos a um fundo branco, cuja extensão se limita a última inflexão do corpo da peça.

b) Os padrões gráficos estão delimitados por faixas vermelhas, associadas ao lábio e as inflexões do corpo da vasilha.

c) Nos campos relacionados ao lábio, gargalo ou pescoço de ambas vasilhas foram traçados pares de finas linhas vermelhas que compõe linhas vazadas com o interior 
ADRIANA SCHMIDT DIAS et al - O discurso dos fragmentos ...

branco. Estas linhas estão dispostas diagonalmente formando triângulos, que são o módulo básico do desenho. O preenchimento do espaço se dá pela combinação destes módulos no sentido superior e inferior, ou seja, entre cada triângulo se coloca outro em posição invertida.

d) Nos campos a partir da primeira inflexão do corpo ou ombro o padrão de linhas duplas vermelhas sobre o fundo branco vazado se mantém, assumindo o desenho formas mais complexas, sendo o espaço preenchido pela combinação dos módulos no sentido superior e inferior. As linhas possuem uma parte reta e vertical em relação à boca da vasilha, que se curvam em ângulos de $90^{\circ}$, formando meias-calotas. A combinação destas linhas forma o módulo do desenho, que lembra a forma de um cálice.
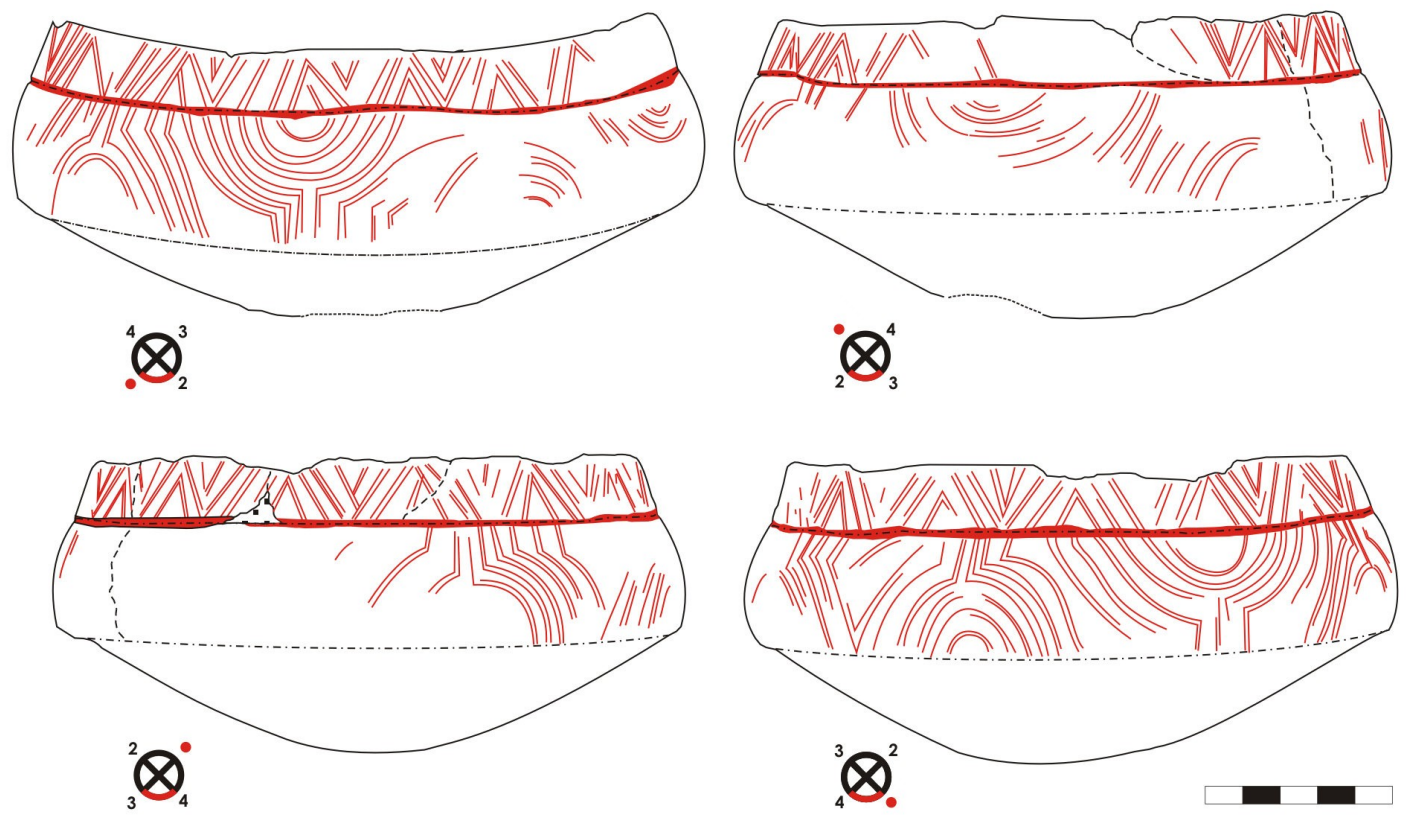

Figura 3 - Vista Externa Cambuchi Caguabá (T-476) - Sítio RS-LN-47: Calipso, Osório 
No cambuchi caguabá, há uma certa continuidade entre as linhas do primeiro e segundo módulo, associando triângulos e cálices invertidos e vice-versa, padrão não observado no cambuchi, onde predomina o tema dos triângulos nos dois primeiros módulos e dos cálices em espelhamento nos dois seguintes. Ainda quanto ao cambuchi caguabá, internamente a vasilha possui um banho vermelho, sobre o qual está representado um grafismo que consiste em uma cruz a partir da qual linhas sinuosas partem preenchendo o espaço interno da vasilha. Este grafismo foi realizado com tinta preta e a espessura e forma irregular dos traços sugere que tenha sido elaborado com os dedos (Figuras 3, 4 e 5).

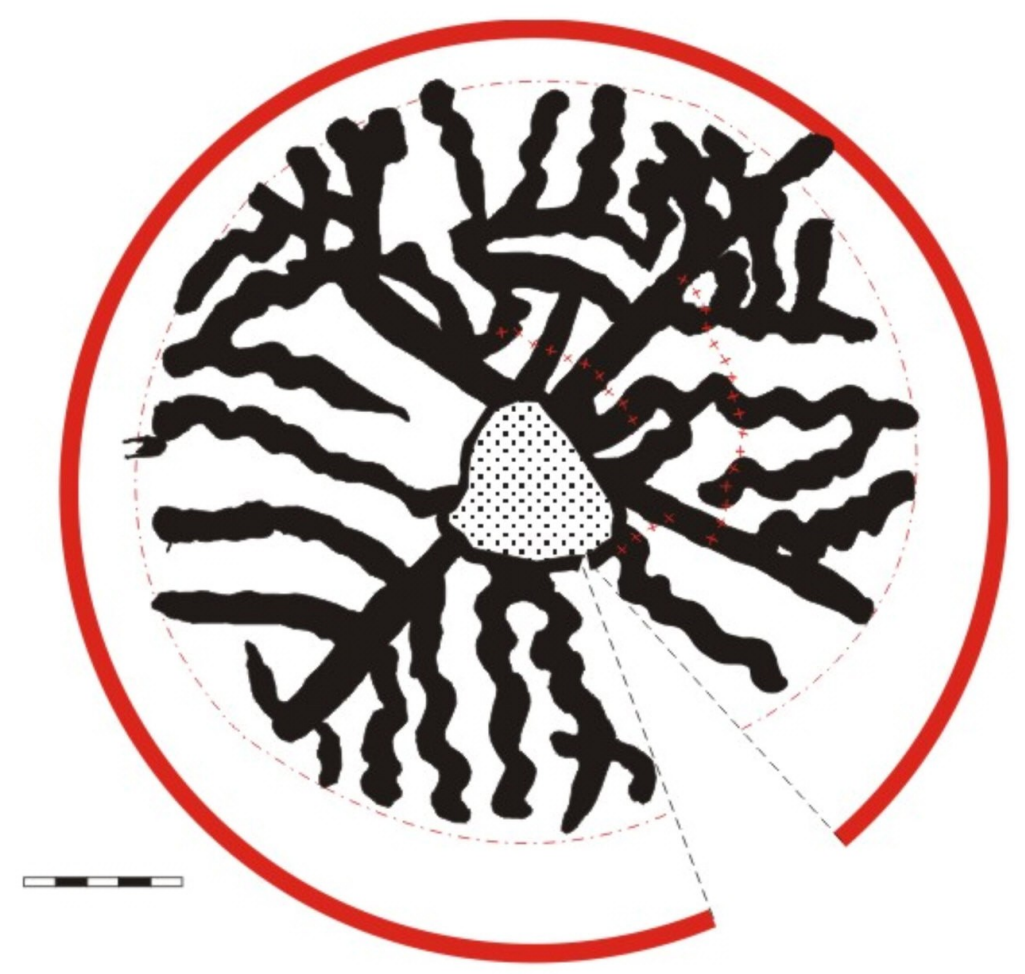

Figura 4 - Vista Interna Cambuchi Caguabá (T-476) - Sítio RS-LN-47: Calipso, Osório 

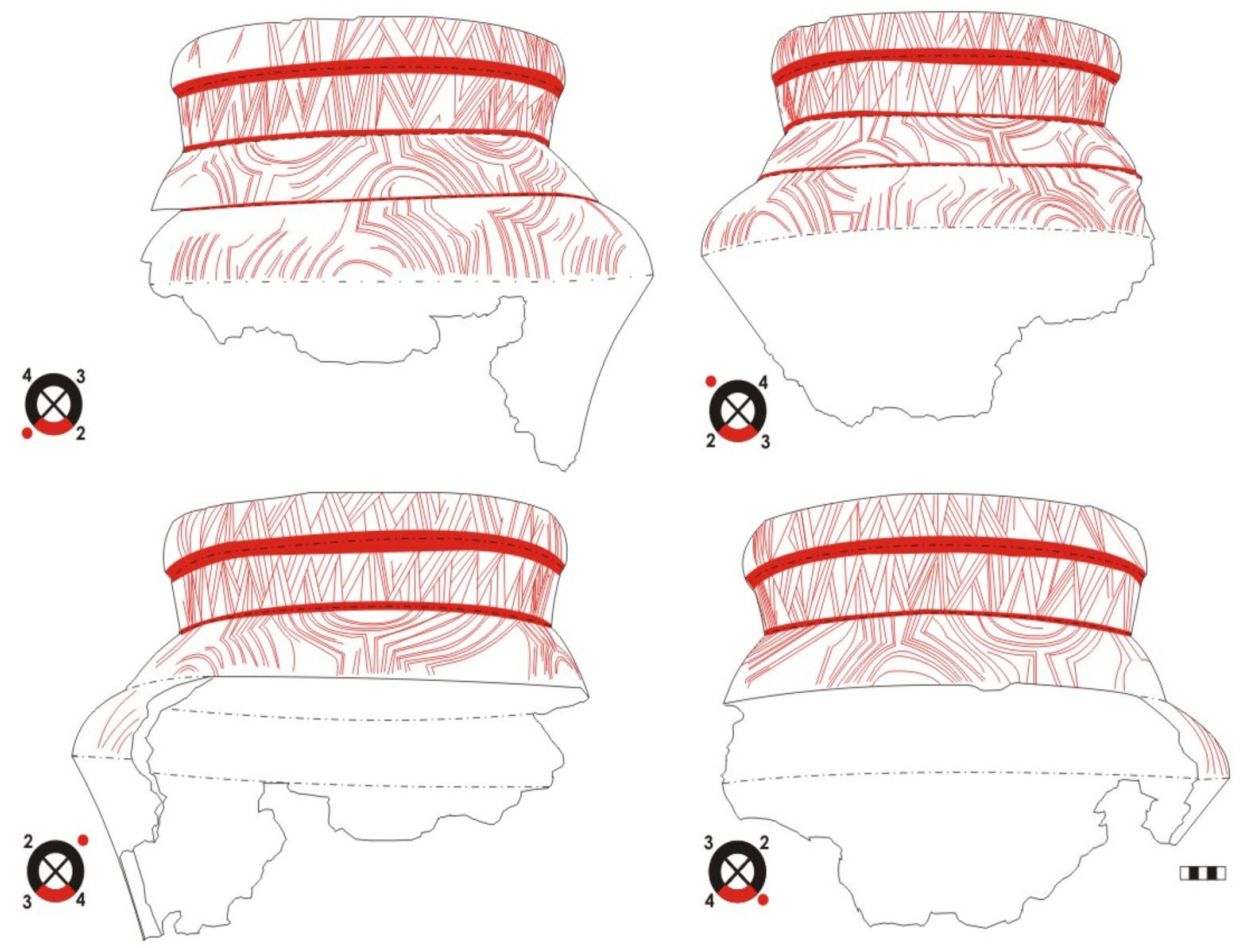

Figura 5 - Cambuchi (T-1 184) - Sítio RS-LN-47: Calipso, Osório

As vasilhas pintadas associadas ao conjunto funerário do sítio RSVZ-41 apresentam padrões gráficos distintos do conjunto anterior e uma maior diversidade interna. No entanto, também estão presentes pontos de conexão quanto aos padrões de distribuição e associação dos motivos relacionados a duas categorias funcionais distintas, marcando um ritmo homogêneo nas regras de composição. O cambuchi caguabá possui contornos simples, com apenas uma área pintada. Sobre o lábio foi aplicada uma faixa vermelha, delimitando o início da área a ser pintada, que compreende o espaço entre a borda e o ponto de maior diâmetro da peça (inflexão do bojo). Nela, sob fundo branco, foram aplicadas verticalmente, mas levemente inclinadas, finas linhas duplas vermelhas que são o módulo do desenho. Em intervalos irregulares há uma mudança na aplicação das linhas, que tomam a inclinação oposta, formando um ângulo agudo, estando o final da área pintada também 
demarcado pela presença de uma faixa vermelha na inflexão do bojo. A face externa desta vasilha apresenta-se escurecida, estando recoberta de fuligem, o que sugere a possibilidade de um uso secundário associado também a atividades de cocção (Figura 6).
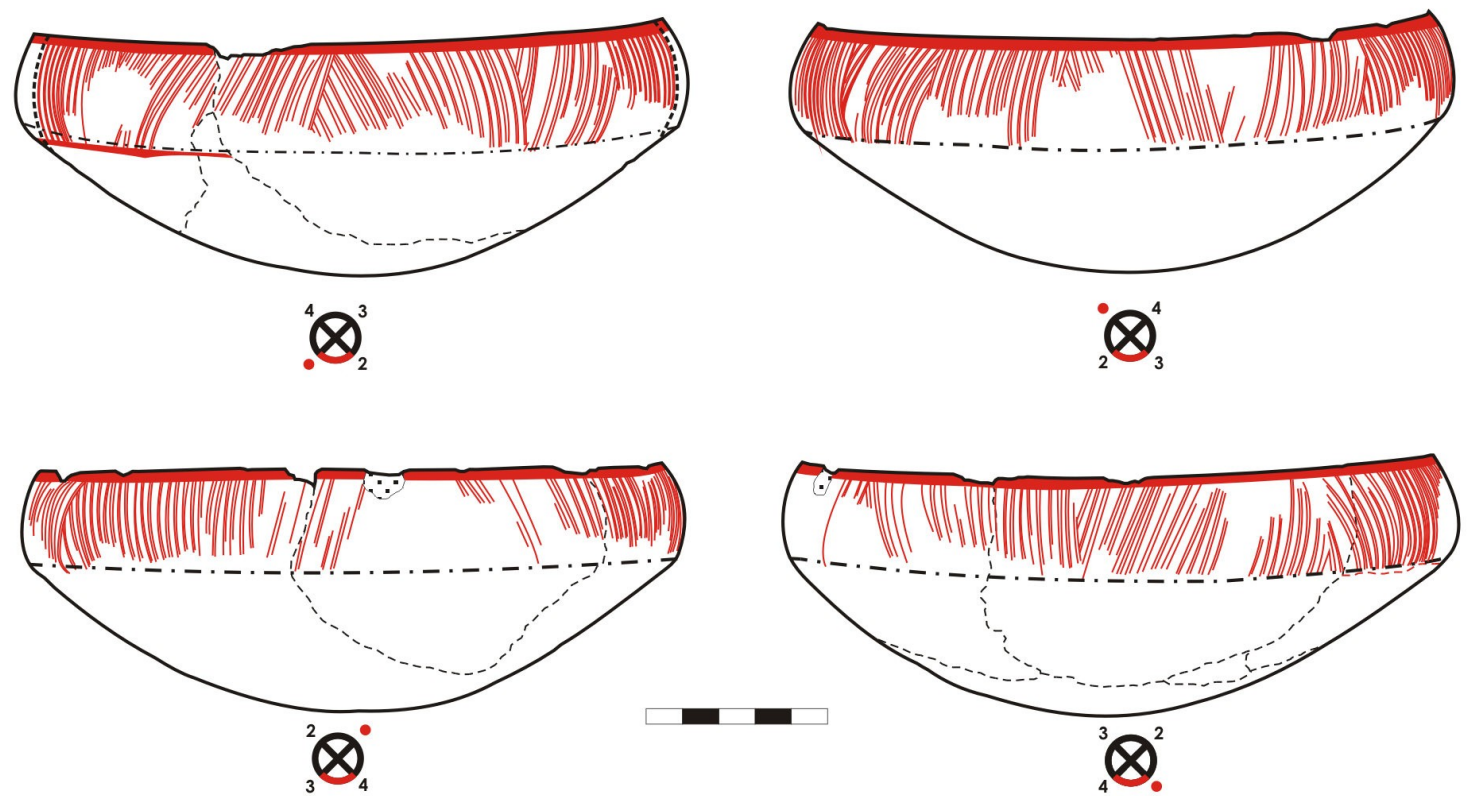

Figura 6 - Cambuchi Caguabá (T 139) - Sítio RS-VZ-41: Jaboticaba 1, Tenente Portela

Quanto ao cambuchi, este apresenta uma particularidade com relação à distribuição dos padrões de cores observados nas demais vasilhas, apresentando um fundo vermelho sobre o qual se distribuem os grafismos compostos por linhas traçadas em branco. No entanto, em grande parte da peça a tinta branca se desgastou, e os padrões gráficos que visualizamos são vestígios ou negativos destes traços. Os pontos de inflexão também foram destacados com faixas brancas, porém por apresentarem-se desgastados somente foram visualizadas nas 
ADRIANA SCHMIDT DIAS et al - O discurso dos fragmentos ...

restrições do pescoço e entre os ombros. Nos dois primeiros campos relacionados ao gargalo ou pescoço e a primeira inflexão ou ombro, observamos o mesmo padrão representado no cambuchi caguabá, no qual sobre o fundo vermelho foram aplicadas linhas brancas diagonais, que são o módulo do desenho. Estas variam de inclinação em intervalos mais regulares formando ângulos agudos. Neste caso, o grande tamanho da peça permite, pela repetição dos traços, a conjunção de certas linhas diagonais cujas extremidades se encontram formando triângulos que são o módulo principal do desenho. Os módulos preenchem o espaço sendo dispostos na posição superior e inferior, ou seja, entre os módulos é colocado outro invertido. É na terceira área pintada que observamos um padrão de grafismos distinto, no qual linhas verticais e horizontais que se encontram em ângulos de $90^{\circ}$, formando quadrados que são o módulo do desenho. $O$ espaço é preenchido dispondo-se os módulos a partir da faixa de inflexão superior e inferior, de forma que haja entre eles espaços vagos. A sensação visual, assim, pode enfatizar tanto a composição de quadrados quanto a imagem de cruz em negativo que se forma entre eles (Figura 7).

Destacamos ainda que embora os padrões gráficos variem para ambos os contextos regionais, podemos observar uma manutenção nas regras de distribuição dos grafismos associadas a categorias funcionais específicas. Nos cambuchi caguabá, as regras comuns associam-se a delimitação dos campos por faixas vermelhas e a distribuição dos grafismos até o último ponto de inflexão da vasilha, quando não há aplicação de pintura. Nos cambuchi também observamos a delimitação de campos por faixas e uma variação de conteúdo dos padrões gráficos quanto a sua posição na vasilha, estando um primeiro tema aplicado a porção superior da vasilha (em ambos os casos associados a linhas inclinadas que formam triângulos) e um tema distinto associado na última inflexão.

Procuramos ampliar a análise das variações temáticas dos grafismos para outras categorias de vasilhas pintadas associadas a contextos domésticos. Neste caso, a coleção de fragmentos pintados do sítio RS-LN-35: Bassani 1, sítio que se caracteriza como uma grande casa comunal, apresentou padrões distintos dos observados nas outras 

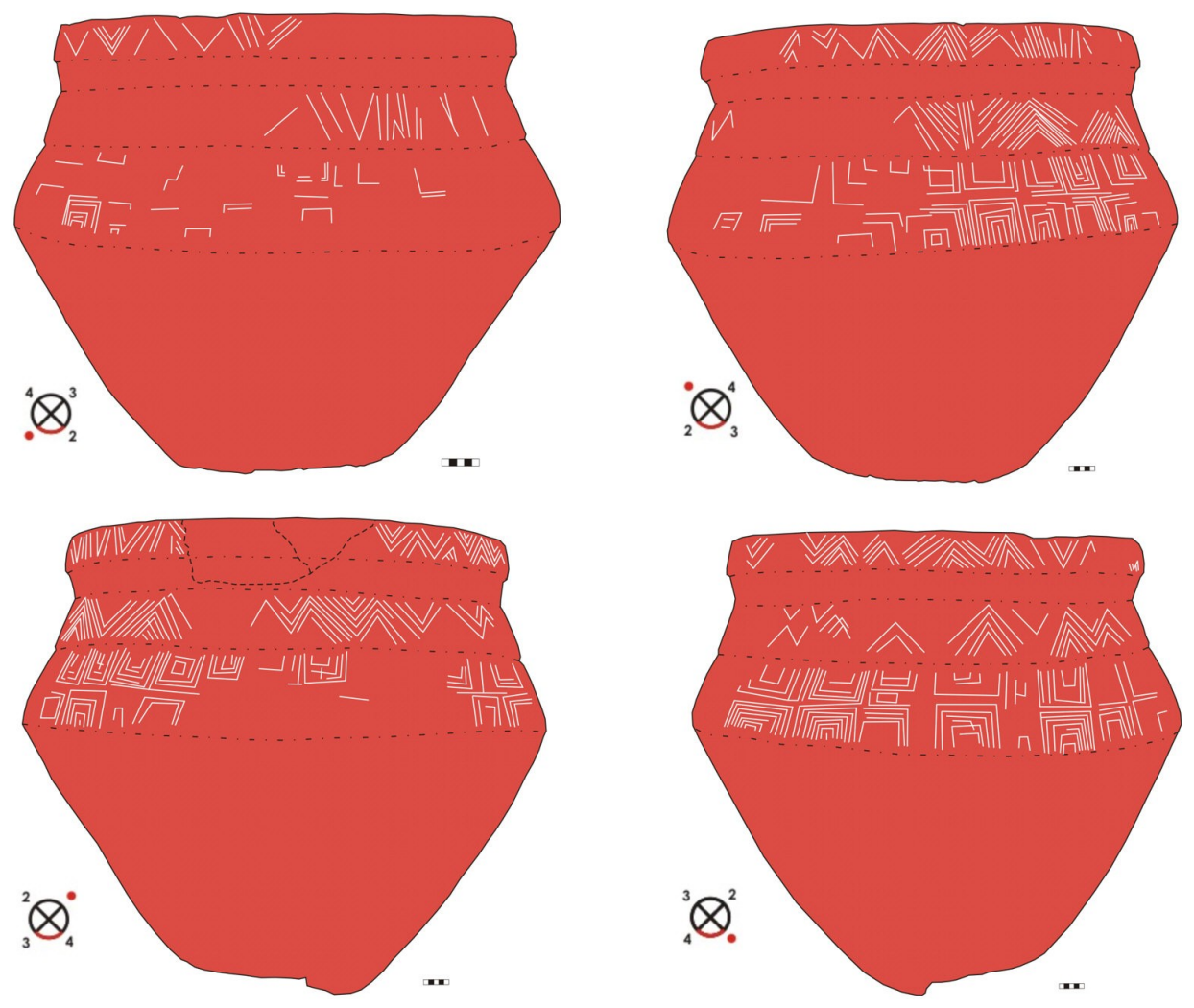

Figura 7 - Cambuchi (T 163) - Sítio RS-VZ-41: Jaboticaba 1, Tenente Portela

coleções. No entanto, para este conjunto também ocorrem, em alguns casos, a reprodução de padrões similares de grafismos associados a distintas categorias funcionais de vasilhas, neste caso os cambuchi caguabá e os tembiru. Um primeiro padrão, associado a um fragmento de tembiru e a um maior número de fragmentos de cambuchi caguabá, está representado por finas linhas duplas vermelhas, semicirculares ou ondulares, aplicadas sobre fundo branco. As figuras formadas preenchem o espaço relacionando a concavidade de uma linha com o início de outra. Assim, do interior de um semicírculo partem as linhas que originarão outro, e desta forma as figuras estão todas encaixadas. Os módulos de representação estão distribuídos de acordo com um padrão de ondulações que se interconectam, formando faixas nas faces 
externas tanto nos gargalos e corpos dos cambuchi caguabá, quanto na face interna do tembiru (Figura 8).
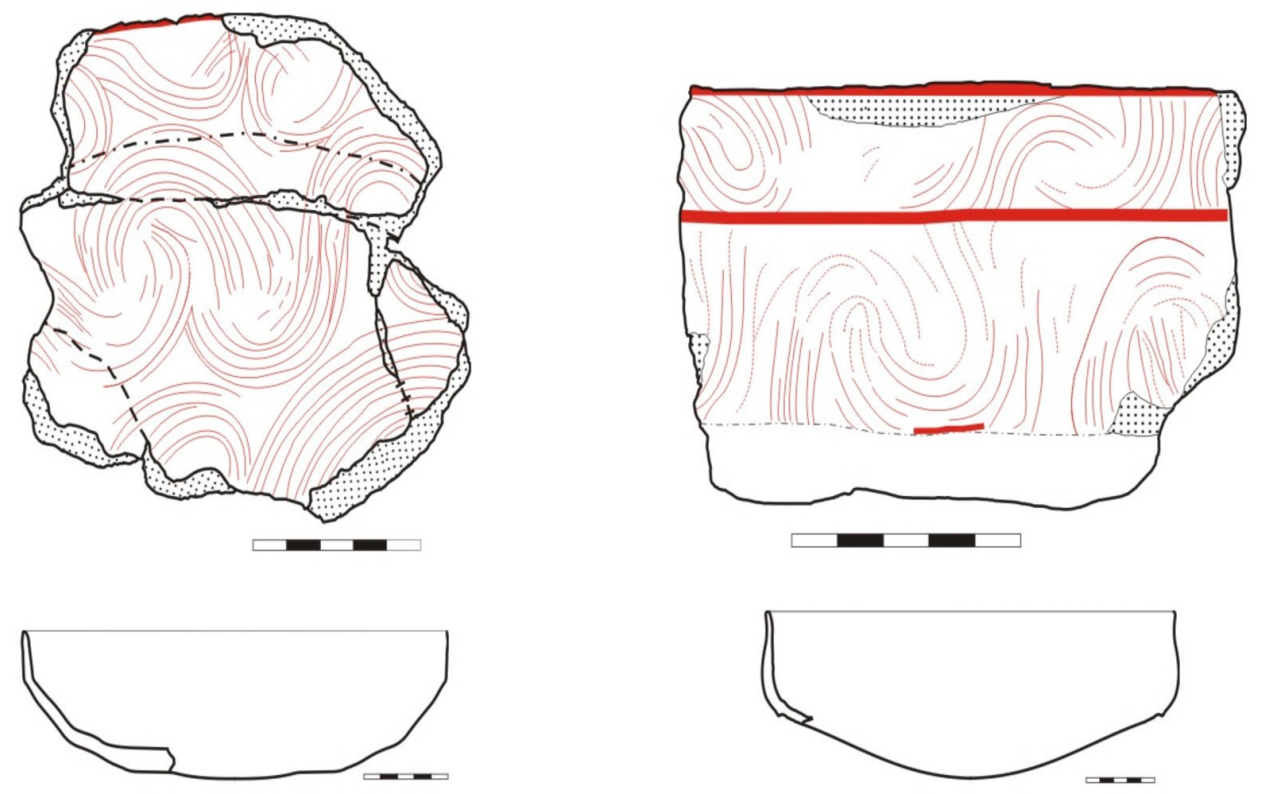

Figura 8 - Fragmentos de Bordas de Tembiru (esquerda) e Cambuchi Caguabá (direita) - Sítio RS-LN-35: Bassani 1, Capão da Canoa

Um segundo padrão associa-se a um fragmento de tembiru e a um fragmento de lábio de cambuchi caguabá. Em ambos os casos o lábio das peças apresenta uma faixa vermelha. Na porção interna do tembiru estão aplicadas finas linhas duplas vermelhas sobre fundo branco, formando conjuntos que se distribuem com um certo espaçamento regular entre si, iniciando-se em uma das extremidades da peça e seguindo até o lado oposto. Este padrão repete-se na face externa do fragmento de cambuchi caguabá. Nesta coleção também foram identificados outros padrões de representação gráfica, porém correspondem a fragmentos de corpo, o que impede a reconstrução das formas e sua associação a categorias funcionais de vasilhas. Destacam- 
se dois padrões que apresentam associação de linhas curvas e retas em ângulos de $90^{\circ}$ : um primeiro formando figuras fechadas, no qual linhas retas delimitam linhas curvas em forma de calota (um dos fragmentos apresentou associação de pintura em preto, vermelho e branco e pintura interna com dedos) e um segundo representa uma variação do padrão de faixas com ondulações, apresentando uma inflexão em uma das terminações das ondas (Figura 9).
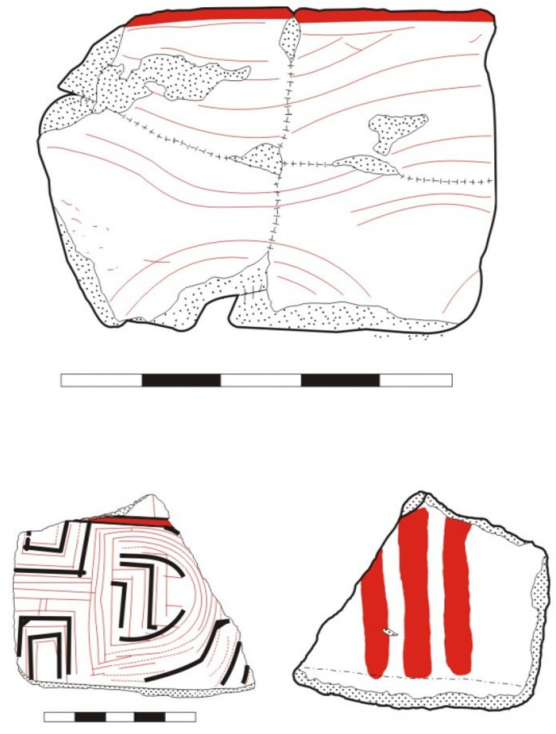
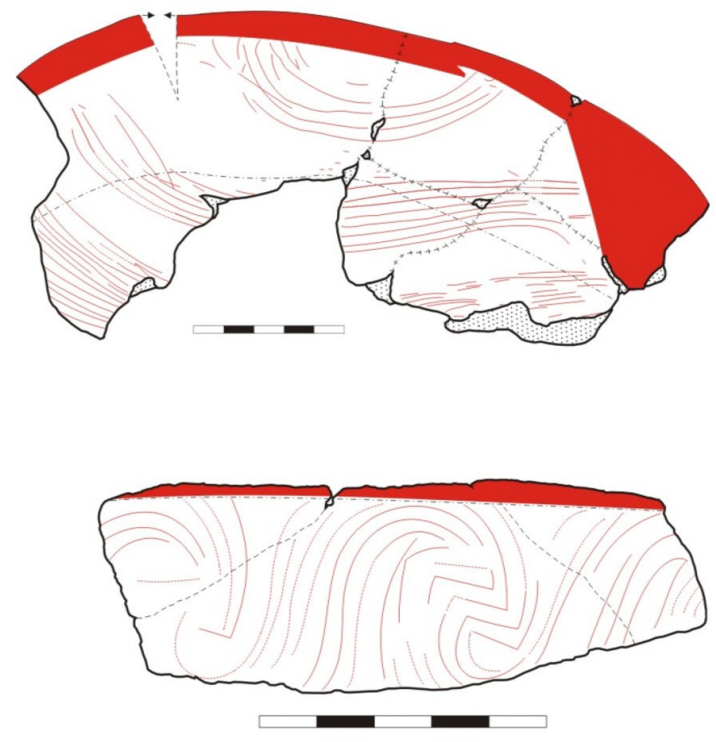

Figura 9 - Variações de padrões gráficos na coleção de fragmentos cerâmicos do sítio RS-LN-35: Bassani 1, Capão da Canoa

Expandindo a comparação de padrões gráficos para a categoria tembiru em âmbito regional, observa-se no único exemplar identificado para o vale do rio da Várzea junto ao sítio RS-VZ-3: Porto Lucena um padrão similar de composição ao identificado para esta categoria funcional na coleção do sítio RS-LN-35: Bassani 1. Este tembiru parece ter sido usado para carbonizar algum material em seu interior, pois o fundo branco da pintura foi quase totalmente enegrecido, porém, as 
pinturas em vermelho não foram alteradas. Seu módulo gráfico também é formado por uma composição de linhas curvas, cujos espaços são preenchidos por pontos. O lábio possui a mesma faixa vermelha identificada em todas as vasilhas. Dele partem conjuntos de três módulos de linhas que fazem um movimento ondulante que se estende entre as bordas da vasilha: seguem retas até um ponto, se curvam e voltam, para novamente se curvar e assim sucessivamente. $O$ interior das linhas foi mantido em branco e o espaço vazio entre os módulos foi preenchido com pontos vermelhos de tamanho regular. $\mathrm{O}$ exterior desta vasilha foi pintado com faixas pretas verticais em relação à borda, aplicadas diretamente sobre a superfície cerâmica, que por sua espessura e irregularidade podem ter sido aplicados com os dedos (Figura 10).
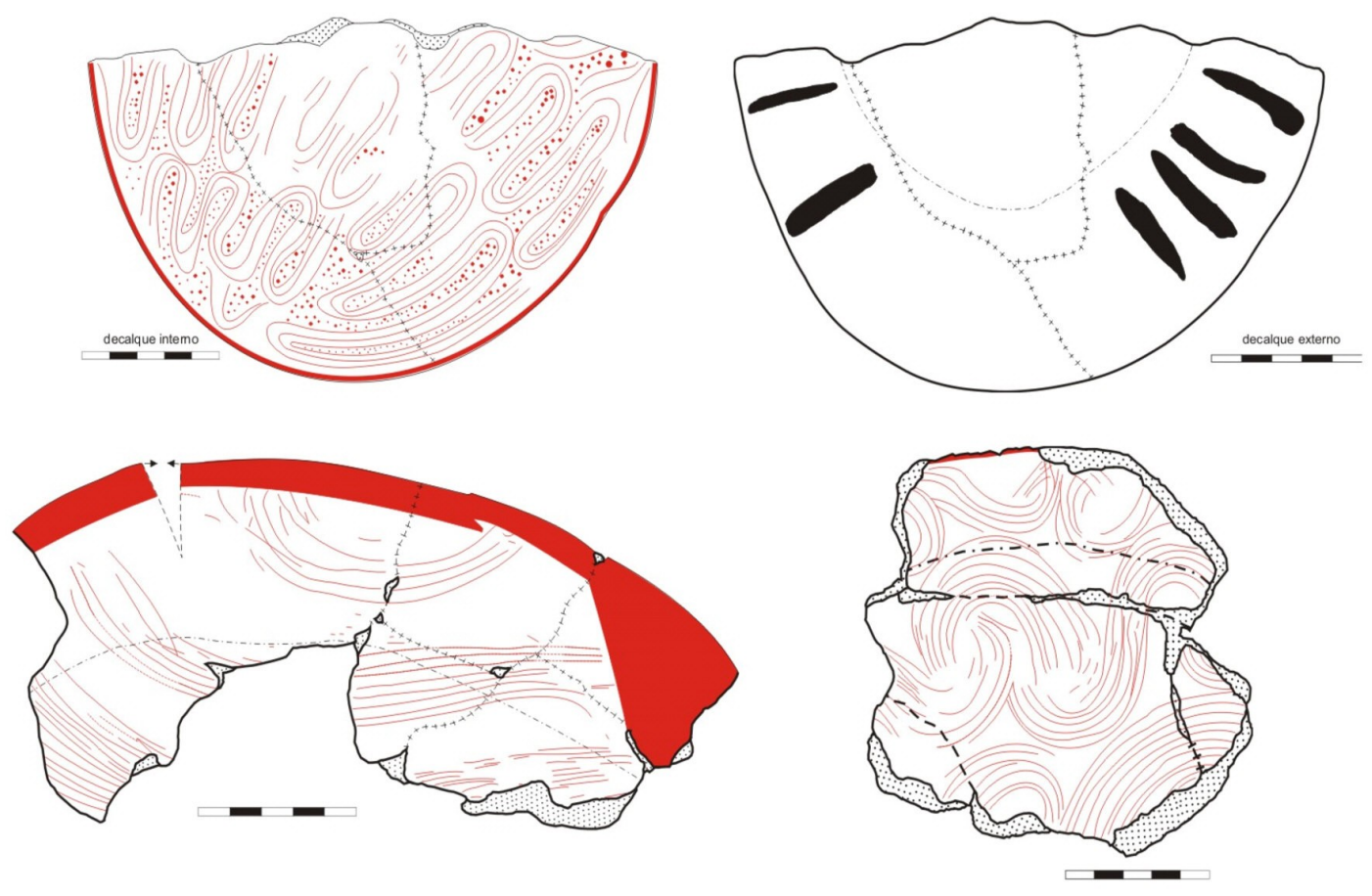

Figura 10 - Parte superior da figura: Face interna e externa de Tembiru ( $\mathrm{T}$ 659), associado ao sítio RS-VZ-3: Porto Lucena. Parte inferior: representação gráfica da face interna de fragmentos de Tembiru, associados aos sítio RS-LN35: Bassani 1 
ADRIANA SCHMIDT DIAS et al - O discurso dos fragmentos ...

\section{Considerações finais}

Este estudo exploratório permite levantar três questões iniciais que podem orientar futuras pesquisas sobre o tema. Em primeiro lugar, podemos observar que não há especificidades quanto ao tipo de padrão gráfico relacionado a distintas categorias funcionais de vasilhas. Em segundo lugar, percebe-se a variação de padrões gráficos nas comparações inter-sítios, representadas tanto no contexto local do litoral norte, quanto no contexto regional do vale do rio da Várzea, noroeste do Estado. Um terceiro ponto que se destaca é que independente da variação dos padrões gráficos em âmbito local e regional sua distribuição nas vasilhas segue as mesmas regras de composição textual, variando de acordo com as distintas categorias funcionais de vasilhas.

Neste ponto, voltamos a questão inicial que norteou esta pesquisa: a quais aspectos sócio-cosmológicos estariam influenciando a variação dos padrões gráficos da cerâmica Guarani pré-colonial? No caso dos sítios do litoral norte, sugerimos duas possibilidades contextuais que podem nortear inicialmente esta a reflexão: o contexto ritual ao qual esta cerâmica está associada e a função dos padrões gráficos como elementos informativos de pertencimentos sociais distintos. Nos casos analisados no litoral norte, percebemos uma variação de padrões na comparação inter-sítios que está em primeira instância relacionada a contextos rituais distintos. No caso do sítio RS$\mathrm{LN}-47$, observamos duas vasilhas funcionalmente distintas que apresentam o mesmo padrão gráfico, associadas a um sepultamento primário em cova e a um sepultamento primário em urna. Em um primeiro momento, poderíamos pensar em padrões específicos ao ritual funerário. Porém a associação a um destes sepultamentos de cerâmicas de uso cotidiano, relacionados aos fragmentos de yapepó que cobrem os pés e o cabeça do morto, indicam e reforçam a idéia de uso secundário das vasilhas pintadas no ritual funerário, apoiadas nas fontes etno-históricas e por estudos de marcas de utilização de vasilhas pintadas (NEUMANN, 2007). Portanto, sugerimos que a presença de um padrão gráfico similar nas vasilhas associadas aos dois sepultamentos estaria sinalizando, em ultima instância, redes sociais comuns a ambos 
ADRIANA SCHMIDT DIAS et al - O discurso dos fragmentos ...

indivíduos - levantamos a hipótese de que os grafismos presentes no acompanhamento funerário, em última instância, sinalizariam pertencimento a determinadas famílias extensas (teii).

Seguindo esta mesma lógica, a variação de padrões gráficos presentes no sítio RS-LN-35, poderia também estar sinalizando aspectos de alteridade entre aldeias para o contexto regional do litoral norte. Contudo, há limitações amostrais que impedem o aprofundamento desta linha de análise, devido à ausência de datações e escavações mais amplas para ambos os sítios que permitiriam melhor explorar os aspectos cronológicos vinculados a esta hipótese. Lembramos que o sítio RS-LN-35 possui datações entre 1000 e 800 anos atrás, sendo estas até o presente as datações mais antigas para ocupação Guarani da área que se estende até o século XVII. Desta forma, esta variação pode estar relacionada a mudanças culturais ao longo dos 600 anos de ocupação tradicional desta região. No entanto, as cerâmicas pintadas deste sítio remontam a contextos rituais associados às áreas domésticas, relacionados a atividades de servir bebidas e alimentos. Este fator contextual pode também estar relacionado a variação dos padrões gráficos observados, estando mais estritamente associados a redes de sociabilidade vinculadas as festas e a rituais de natureza distinta da funerária, vinculados, por exemplo, ao ritual antropofágico. Evidencias que sustentariam esta hipótese não se preservaram no sítio em questão, porém em escavações realizadas em áreas domésticas no sítio Guarani de Candelária, vale do rio Pardo (RS), foram identificados ossos humanos fraturados, com marcas de queima e corte, em associação com fogueiras e lixeiras domésticas, repletas de cerâmica e faunísticos (SCHMITZ et al, 1990).

Podemos ainda perceber na comparação entre os conjuntos analisados evidências de variações regionais demarcadas pelos grafismos, observando-se uma maior tendência nos cambuchi e cambuchi caguabá a representações geométricas no vale do rio da Várzea e a composições variadas com predomínio de padrões de associação de linhas sinuosas para o litoral norte. Por sua vez, esta variação não é identificada nos tembiru, onde predominam para ambas as áreas as representações de linhas sinuosas distribuídas em faixas. Estas variações nas características de composição podem estar 
ADRIANA SCHMIDT DIAS et al - O discurso dos fragmentos ...

sinalizando distintas redes sócio-políticas de caráter regional que integrariam distintos Guará. Contudo, esta comparação regional que intentamos realizar encontrou limitações em função da qualidade de preservação das amostras estudadas, devendo ser redimensionada a partir da avaliação de outros acervos institucionais. Destaca-se, no entanto, que a distribuição dos padrões gráficos entre as distintas categorias funcionais de vasilhas em ambas as regiões segue as mesmas regras de composição, indicando contextos socio-cosmológicos similares de produção e uso dos grafismos.

\section{Referências bibliográficas:}

BROCHADO, José Proenza. Alimentação na floresta tropical. Porto Alegre: IFCH/UFRGS, 1977. 103p. (Coleção Cadernos, 2).

An ecological model to the spread of pottery and agriculture into Eastern South América. 1984. 306f. Tese (Doutorado em Antropologia) - University of Illinois, Urbana-Champaign, [1984].

BROCHADO, José Proenza; MONTICELLI, Gislene. Regras práticas na reconstrução gráfica das vazilhas de cerâmica Guarani por comparação com vasilhas inteiras. Estudos Ibero-Americanos, Porto Alegre, v. 20, n. 2, p. 107-118, dez. 1994.

BROCHADO, José Proenza; MONTICELLI, Gislene.; NEUMANN, Eduardo S. Analogia etnográfica na reconstrução gráfica das vasilhas Guarani arqueológicas. Veritas, Porto Alegre, v. 35, n. 140, p. 727-743, dez. 1990.

CARLE, Mirian Baptista. Investigação arqueológica em Rio Grande: uma proposta da ocupação Guarani pré-histórica no Rio Grande do Sul. 2002. 253f. Dissertação (Mestrado em História) - Pontifícia Universidade Católica do Rio Grande do Sul, [2002].

GALLOIS, Dominique. Arte iconográfica Waiãpi. In: VIDAL, Lux (Org.). Grafismo Indígena: estudos de Antropologia Estética. São Paulo: Edusp/Studio Nobel, 1992. p. 209-230.

LA SALVIA, Fernando; BROCHADO, José Proenza. Cerâmica Guarani. Porto Alegre: Posenato Arte e Cultura, 1989. 175p.

MULLER, Regina P. Tayngava, a noção de representação na arte gráfica Assuiní do Xingu. In: VIDAL, Lux (Org.) Grafismo Indígena: estudos de Antropologia Estética. São Paulo: Edusp/Studio Nobel, 1992. p. 231-248. 
ADRIANA SCHMIDT DIAS et al - O discurso dos fragmentos ...

NEUMANN, Mariana Araújo. Outra Vasilha para uma Nova Fervura: contribuições para o Estudo Funcional da Cerâmica Guarani. In: Reunión Internacional de Teoría Arqueológica en América del Sur/Inter-Congreso del WAC, 4, 2007. Catamarca (Argentina), 2007.

Nande rekó: diferentes jeitos de ser Guarani. 2008. Dissertação (Mestrado em História) - Universidade Federal do Rio Grande do Sul, [2008].

NOELLI, Francisco Silva. Sem Tekhoa não há Tekó: em busca de um modelo etnoarqueológico da aldeia e da subsistência Guarani e sua aplicação a uma área de domínio no delta do rio Jacuí, Rio Grande do Sul. 1993. Dissertação (Mestrado em História Ibero-Americana) - Pontifícia Universidade Católica do Rio Grande do Sul, [1993].

As hipóteses sobre os centros de origem e as rotas de expansão dos Tupi. Revista de Antropologia, São Paulo, v. 39, n. 2, p. 7-54, 1996 a.

- Resposta a Eduardo Viveiros de Castro e Greg Urban. Revista de Antropologia, São Paulo, v. 39, n. 2, p. 105-118, 1996 b.

- The Tupi: explaining origin and expansion in terms of archaeology and historical linguistics. Antiquity, Cambridge, v. 72, n. 277, p. 648-663, 1998.

A ocupação humana na região sul do Brasil: arqueologia, debates e perspectivas - 1872/2000. Revista USP, São Paulo, v. 44, n. 2, p. 218-269, 1999/2000.

NOELLI, Francisco Silva; BROCHADO, José Proenza. O cauim e as beberragens dos Guarani e Tupinambá: equipamentos, técnicas de preparação e consumo. Revista do Museu de Arqueologia e Etnologia, São Paulo, v. 8, p. 117-128, 1998.

PROUS, André. Arte Pré-histórica do Brasil. Belo Horizonte: Ed. CI Arte, 2007.

ROGGE, Jairo H. Adaptação na floresta subtropical: a Tradição Tupiguarani no médio rio Jacuí e no rio Pardo. Arqueologia do Rio Grande do Sul, Brasil - Série Documentos, São Leopoldo, v. 6, p. 3-156, 1996.

SCHMITZ, Pedro Ignácio. A cerâmica Guarani na Ilha de Santa Catarina e a cerâmica da Base Aérea. Pesquisas Antropologia, São Leopoldo, n. 3, p. 268-324, 1959.

- Migrantes da Amazônia: a Tradição Tupiguarani. In: KERN, A. (Org.). Arqueologia pré-histórica do Rio Grande do Sul. Porto Alegre: Mercado Aberto, 1991. p. 295-330.

SCHMITZ, Pedro. I. et al. Uma aldeia Tupiguarani: projeto Candelária, RS. Arqueologia do Rio Grande do Sul, Brasil - Série Documentos, São Leopoldo, v. 4, p. 7-130, 1990. 
ADRIANA SCHMIDT DIAS et al - O discurso dos fragmentos ...

SOARES, André Luís. Guarani: organização social e arqueologia. Porto Alegre: EDIPUCRS, 1997. 259p.

Contribuição à Arqueologia Guarani: estudo do Sítio Röpke. Santa Cruz do Sul: Editora UNISC, 2005.

TOCCHETTO, Fernanda. Possibilidades de interpretação do conteúdo simbólico da arte gráfica Guarani. Revista do Museu de Arqueologia e Etnologia, São Paulo, v. 6, p. 33-45, 1996.

URBAN, Greg. On the geographical origins and dispersions of Tupi languages. Revista de Antropologia, São Paulo, v. 39, n. 2, p. 61-104, 1996.

VAN VELTHEM, Lúcia. Arte indígena: referentes sociais e cosmológicos. In: GRUPIONI, Luiz Donisete (Org.). Índios no Brasil. São Paulo: Global editora, 1998. p. 83-92.

VIDAL, Lux; MULLER, Regina. Pinturas e adornos corporais. In: Suma Etnológica Brasileira: Arte índia, v. 3. Petrópolis: Vozes/Finep. 1987. p. 119-148.

VIVEIROS DE CASTRO, Eduardo. Comentários ao artigo de Francisco Noelli. Revista de Antropologia, São Paulo, v. 39, n. 2, p. 55-60, 1996. 